\title{
Knowledge and knowers in teaching and learning: an enhanced approach to curriculum alignment
}

\section{Sherran Clarence}

(Received 16 November 2015; accepted 4 June 2016)

\begin{abstract}
John Biggs' well-known curriculum design approach, constructive alignment, is widely used in higher education in the United Kingdom, Australia and South Africa. Developed with one dominant account of learning through curriculum, this approach has a gap in terms of accounting for other kinds of knowledge building, and associated knower development. This paper proposes a complementary approach that accounts for different kinds of knowledge and knower building. Using Legitimation Code Theory's concept of Specialisation, the paper argues that accounting for what makes a discipline 'special' in terms of its basis for legitimate achievement can enable curriculum writers to align curricula more effectively with that basis in different disciplines. Using a case study approach, this paper shows how this tool can provide lecturers and academic development practitioners with a useful mode of analyzing curriculum alignment to more ably account for differential development of disciplinary knowledges and knowers.
\end{abstract}

\section{Introduction}

Since its initial appearance in the late 1990s, John Biggs' concept of constructive alignment as a tool for designing curriculum in higher education has become popular in the United Kingdom, South Africa, Australia and New Zealand (Kahn, 2015). Simply put, this approach to designing curricula requires that they be aligned in service of an end-goal of demonstrable student learning. Beginning with learning outcomes, moving through teaching and learning activities and assessment and ending in evaluation, all the steps of this process need to be clearly connected, so that what students are supposed to be learning is taught, assessed and evaluated, creating a clear connection between aims and outcomes (Biggs, 1996, 2012).

This approach is now widely used, with several authors indicating its usefulness as a tool for curriculum design (Edström, 2008; Joseph and Juwah, 
2012; Treleaven and Voola, 2008). However, this paper, while acknowledging the need for the aims and outcomes of curriculum to be carefully planned and aligned, acknowledges that there is a gap in this approach that needs to be addressed. According to Kahn (2015), the constructive alignment approach, building on Biggs' earlier work on the SOLO taxonomy, account predominantly for one form of knowledge building in education. This form is aggregative, and similar to Bernstein's account of hierarchical knowledge structures that develop by subsuming and building on prior knowledge (cf. Bernstein, 1999; Kahn, 2015). This leaves other forms of knowledge-building which are less aggregative and more segmented, like Bernstein's horizontal knowledge structures which grow through the introduction of new speakers, ideas, and theories (Bernstein, 1999), underconsidered in the application of such an approach.

Biggs' approach is useful in highlighting the need to interrogate closely the appropriateness of learning outcomes and the aligned teaching, learning, assessment and evaluation that will lead students to achieving those outcomes. However, it is focused largely on pedagogy and the enactment of curriculum, rather than on the knowledge that is included in the curriculum itself, or on the different kinds of knowers students need to become. In essence, there are gaps within the design of constructive alignment that merit further consideration, and the need for complementary approaches to strengthen its applicability across the disciplinary map (Kahn, 2015).

This paper seeks to consider one such complementary approach to enhancing constructive alignment as a useful tool for curriculum design. The paper approaches this consideration from a realist theory of knowledge, particularly that which underpins Legitimation Code Theory (LCT) within the sociology of education. It begins by unpacking in more detail Biggs' formulation of constructive alignment, as well as the potential gaps that could be filled by a complementary approach drawn from LCT, specifically from the dimension of Specialisation. It then moves on to explain what LCT has to offer as an invaluable set of additional tools to enhance a process of constructive curriculum design, before moving on to illustrate the tools in action within a defined case study. 


\section{Constructive alignment and the question of knowledge}

'Constructive alignment' as a tool for curriculum design and renewal is drawn primarily from the work of John Biggs (1996, 2012). This approach advocates designing curricula focused on what students are doing in the classroom, with aligned learning outcomes, teaching and learning activities, assessments and evaluation tasks. In essence, Biggs' model for aligning curricula suggests that all teaching and learning activities and assessments must be able to lead learners towards achieving identifiable outcomes, and activities need to focus on giving students opportunities to engage as far as possible in 'authentic' (Herrington and Herrington, 2006) and 'studentcentred' (O'Neill and McMahon, 2005) learning. Learning and teaching activities should be designed to enable students to construct knowledge and make meaning in ways that connect with and build on their prior learning, and encourage students to be active participants in their own learning.

In developing first the SOLO taxonomy and later constructive alignment (Biggs, 1996), Biggs accounted primarily for one form of knowledge building or learning, that more closely associated with Bernstein's hierarchical knowledge structures (Kahn, 2015) that grow through subsuming and extending established knowledge. This has left a gap where forms of knowledge building or learning that may not be aggregative in the same ways are under-considered (Kahn, 2015). What is important about this in the context of this paper is that, in foregrounding only one broad form of knowledge building Biggs also under-accounted for different kinds of knowers that are developed through encounters with different forms of knowledge building and meaning-making. In other words, in obscuring a set of relations within curriculum - that associated with horizontal knowledge structures, and their curricula and pedagogic practices - Biggs also obscured the development of associated kinds of knowers. Thus, following Kahn (2015) constructive alignment as a useful tool for curriculum development could be expanded and complemented by approaches that can account more adequately for both knowledge and knowers, and for the different ways in which both are developed in higher education.

A significant first step in extending constructive alignment to more adequately account for different forms of knowledge and knower construction is to consider what we mean by knowledge. The argument proposed in this paper is premised on a realist theory of knowledge; that knowledge emerges 
from but cannot be reduced to the contexts in which it is created (Maton and Moore, 2010). In other words, knowledge is not only subjectively created within the minds of those who make and know it. This theory of knowledge acknowledges that there are always two dimensions of learning that should not be conflated: there is an objective dimension - the knowledge itself, and a subjective dimension - those who come to make and hold that knowledge. If we only see knowledge as that which is created in the minds of knowers, rather than as having its own objective properties, we may risk obscuring important differences between commonsense and theoretical knowledge (Wheelahan, 2009) and further make it difficult for students to grasp these as part of a basis for success in university studies.

This paper contends that in order to encourage and enable students to make meaning and build knowledge within their disciplines in appropriate and engaged ways, curriculum designers need to acknowledge that different disciplines have different purposes or aims in terms of who they are trying to enable students to become, how they are trying to encourage students to act, and what they are trying to enable students to know (see Barnett, 2000; Schulman, 2005). In other words, teaching and learning needs to account more fully for different forms of knower and knowledge building across the disciplines. This requires a critical consideration of the underlying organising principles or epistemic and ontological purposes of a discipline, which indicate what counts as legitimate knowledge and legitimate ways of creating and disseminating that knowledge (Maton, 2014).

Using the Specialisation dimension of Legitimation Code Theory (LCT), this paper selects relevant data from one case study within a wider research project undertaken in a South African university as an illustrative example of how constructive alignment could be enhanced. The data analysis reveals one set of underlying organising principles within a discipline that represents a less aggregative form of learning and knowledge building. Thus, it considers a particular set of goals for who the knowers should be and what attributes they should possess to be successful. Possible implications of employing this kind of analysis are discussed in relation to how the findings can open up new conversations between academic staff development practitioners and lecturers, or between lecturers and their students, about what counts as knowledge, in what ways it can come to be known in particular disciplinary fields, and what attributes successful students need to develop over time. 


\section{Conceptual framework}

Legitimation Code Theory, or LCT, is a realist sociological 'toolkit' developed by Karl Maton that subsumes and extends the prior work of mainly Basil Bernstein and Pierre Bourdieu, specifically Bernstein's code theory and Bourdieu's field theory (for a fuller account please refer to Maton 2014, Chapter 2). Specialisation is a dimension of LCT that reveals one set of organising principles or underpinning logics that shape and inform what academic disciplines do with knowledge and associated ways of knowing.

Specialisation, in the context of this paper, posits that all disciplines need to stake their claim to status, recognition and position within higher education, and that they do so by using particular discourses that mark them as having attributes worthy of recognition. For example, Political Science uses, crudely put here for the purposes of brevity, a discourse of critical imagination and analytical thinking that applies theory within the field to understanding and critiquing global or local issues. Political Science knowers construct particular forms of arguments to accomplish this, and to stake claims to legitimacy and status within higher education. Actors within this discourse may and will argue about whether these claims are correct, and whether they should be changed and how. But political science academia globally is marked, broadly speaking, by a discourse of rigorous, empathetic reasoning and argument underpinned by particular methods or ways of engaging with both theory and the application or development of that theory (even if there are contextual differences between universities and national political systems) (see Goodin and Klingeman, 1998).

These claims to status, or legitimacy are based on deeper, often tacit understandings of the principles underlying the knowledge structure within the intellectual field in question (Maton, 2007). Actors and discourses within these intellectual fields, out of which higher education disciplines are drawn, are "selected and recontextualised on the basis of a principle emanating from the knowledge structure, knower structure or. . neither or both" (Maton, 2007, p. 92). If we can understand the discursive practices of the intellectual fields as structures that select, position and empower actors and discourses in different ways, then we can begin to consider the influence that a particular set of discursive practices may have on what we select in developing a curriculum, and how we recontextualise and enact the curriculum knowledge through aligned pedagogic and assessment practices. Different disciplines are 
likely to employ curriculum forms aligned with their aims of, for example, training a particular kind of future professional such as an attorney, or nurturing a particular kind of thinker who could work in a range of professional fields, such as an analyst working for government, an NGO or a private sector company.

Specialisation is employed here as a tool for analysing the organising principles that form the basis for claims to legitimacy within one academic discipline: Political Science. Specialisation considers two dimensions that comprise these organising principles, arguing that there is always knowledge and there are always knowers that need to be considered. Specialisation comprises two sets of relations: epistemic relations (ER), or relations to that which is known, and social relations (SR), or relations to those doing the knowing (Maton, 2007). Considering both relations simultaneously enables curriculum designers and lecturers to think relationally about how they are developing both knowledge and knowers, rather than only seeing one or the other (Maton, 2007, 2014).

Using the analytical distinction between epistemic relations and social relations (ER and SR), LCT conceptualises four specialisation codes (Maton, 2014), which can be used as an analytical tool for 'seeing' and describing the principles underlying curriculum design and teaching. These four codes are represented on a Cartesian plane as points on a compass within which a great deal of variation can be found. Epistemic relations and social relations can be stronger or weaker in relation to one another along two continua, with stronger epistemic relations and social relations signified with ER+ and SR+, and weaker epistemic relations and social relations signified with ER- and SR- (see figure 1 below). 


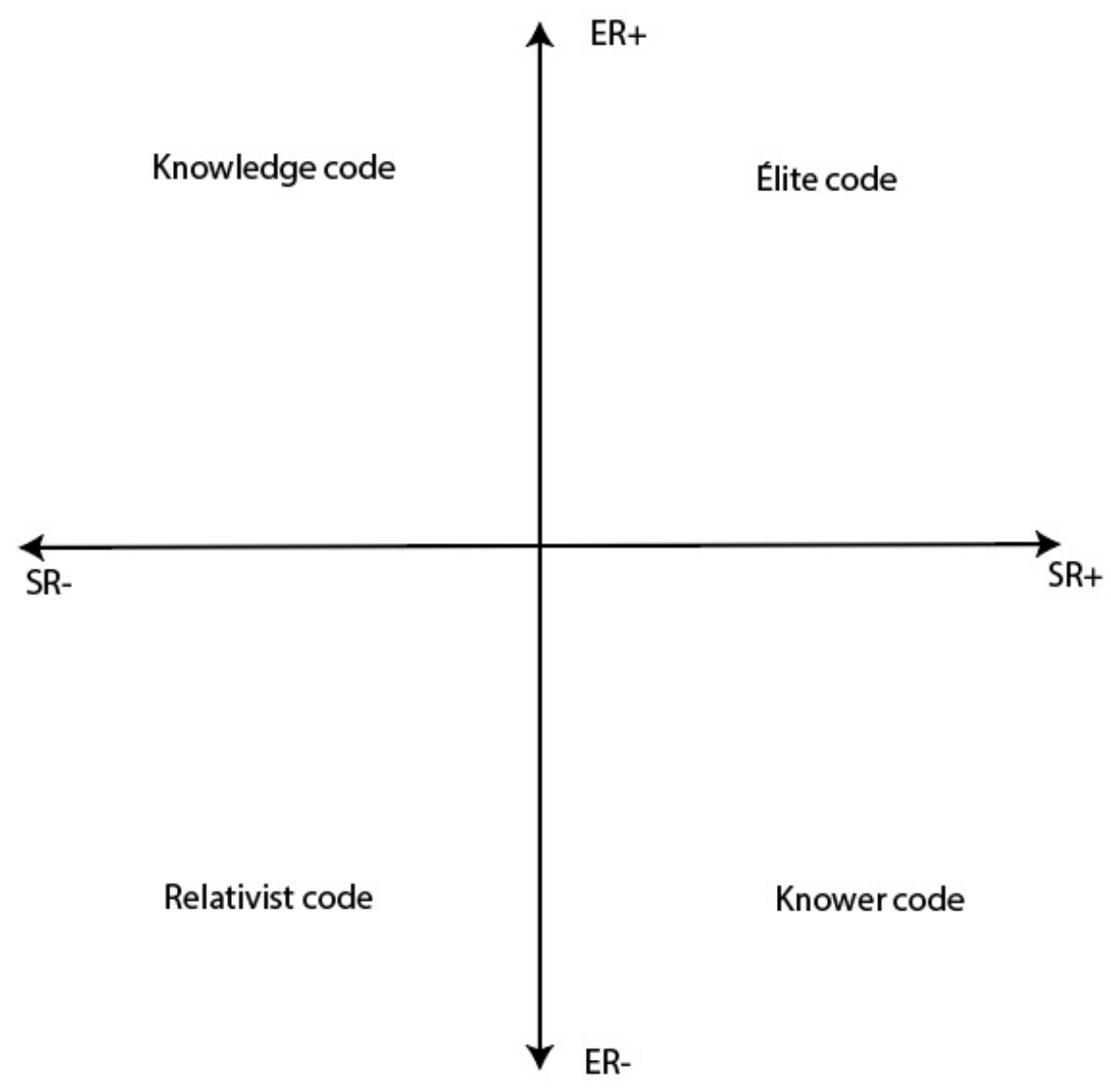

Figure 1: Specialisation codes represented on a Cartesian plane (Maton, 2007, p 96)

The code on the bottom right is the one that will be focused on in this paper, and is termed a knower code (ER-, SR+), indicated by the emphasis on what forms the basis of legitimate achievement within knower code disciplines. With a knower code the disposition of the knower is emphasised, and this disposition can be "innate", learned or "resulting from the knower's social position" (Maton, 2007, p.97). Elsewhere this code is defined as being legitimated on the basis of "a distinct subject of study, the "knower" (Maton 2000, p.87, emphasis in original). Thus the underlying principles of this code privilege who is learning the knowledge, and the personal, professional or social attributes and attitudes they need to develop. Political Science, as we shall see in the next section, represents a knower code.

Before moving on to the case study and analysis of the data, it is important to note that LCT differentiates between the focus of claims to legitimacy and the basis for these claims. The basis of claims to legitimacy is what determines 
the specialisation code of the discipline or field. For example, it can be observed that in political science education learning political theory concepts such as power, sovereignty, freedom, citizenship and so on - is often a focus of teaching. One could therefore believe that the content of the curriculum is largely theoretical and thus that mastering the theory or procedural knowledge it represents is the basis for success. However, while theory is often the focus, the basis for legitimate achievement is rather the selective use of theory to influence, inform and shape the construction, substantiation and defense of arguments, using particular methods of reasoning and arguing that are recognised as valid. This will become clearer in the analysis of the data. While the focus of any curriculum may shift and change over time, and in relatively short periods of time, the basis of legitimacy tends to be more enduring. While it can indeed change, this process of change tends to take place over longer periods of time, and often as a result of more protracted struggles over control of the field, or discipline (cf. Maton, 2014).

\section{Political science as a knower code}

This case study puts into practice the conceptual tools explained in the previous section. The data was generated during a larger study conducted in 2013 (Clarence, 2014). The larger data set comprised interviews with lecturers, extensive field notes and video data generated over 14 weeks of teaching observations in two undergraduate courses, as well as course outlines and lecture notes. The two courses in the study were a first year course in the undergraduate LLB (Law) degree, and a first year Political Science course in the undergraduate BA/BAdmin degree.

The data selected in this paper comes only from Political Science, and only from the course outlines and notes the lecturers make available to their students, which encapsulate their curricular expectations of learning outcomes for the course, as well as indications of teaching and learning activities and assessment tasks. Although these course outlines and guides may give students only a partial view of the kinds of learning that are expected and offered in the whole degree programme, they provide a window into what the discipline regards as important, and thus enable a Specialisation analysis to tease out what the specialisation code of the discipline is, and how this can be 
used to enhance the alignment of learning outcomes and activities with the underlying purposes and goals of Political Science as an academic discipline.

The course guide data were organised and coded using Nvivo10, and the data were analysed for indications of the relative strengths of epistemic relations and social relations indicated in the conveyed learning outcomes and expectations for the course, and lecturers' design of tutorial and assessment tasks. In other words, the data were read for the organising principles and basis of legitimate achievement in Political Science. Relevant parts of the data have been selected in this paper to show how the specialisation code has been heuristically determined, and what this enables lecturers to consider differently in terms of accounting for knowledge and knowers together in aligning their curricula.

The Political Science case study is a first year, first semester foundational course, POL131, divided into two halves: the first half of the course introduces students to basic core concepts used in Political Studies generally, and the second half introduces students to core concepts and methods in the study of International Relations as a sub-discipline. The 2013 study guide (p.1) informs students that:

After completion of POL131 you should be able to:

- Identify, define and describe key concepts in Political Studies, e.g. power, legitimacy and authority.

- Identify, define and describe the key concepts in International Relations, e.g. sovereignty, world order, international anarchy, international political economy, etc.

- Explain Galbraith's theory of power and apply it to South Africa.

- Compare and contrast the key theories of International Relations, e.g. Realism, Liberalism and Marxism.

- Differentiate between and explain selected processes in Political Studies and International Relations, e.g. social activism, development or trade. 
In addition, you should:

- Be able to take notes in class.

- Be able to read with comprehension (understanding), summarise arguments presented in reading and the lectures, and explain these verbally and in writing.

- Be able to do basic research tasks (library use, internet use, course reader use etc.).

- Have the basic skills to write in an academic style (including referencing).

- Present your opinions verbally (in class, tutorials and informal conversations).

- Be more aware of how politics influence society and how you can express your political views.

Indicated as the learning outcomes for the course, these points highlight both knowledge of particular content in the first bulleted list, as well as development of practices, skills and dispositions that the discipline values in the second bulleted list. In terms of practices, the document highlights reading 'with comprehension', and being able to 'summarise arguments' and 'explain these' which is a key precursor to students being able to craft their own arguments. The final two bullet points highlight a disposition that students need to begin developing, that of both having and expressing their own opinions on issues raised in or relevant to the course, and being aware of how 'politics influence society'. This final point indicates a need for students to become more critically aware of politics at work around them, and not just in their coursework.

The separating of these learning outcomes into core knowledge outcomes, as well as more practical and dispositional outcomes is further elaborated on in the Departmental Policy document (2014) that students, staff and tutors in the department have access to, and which sets out the aims of the department in terms of their curriculum, as well as their expectations of both students and staff. This document $(2014$, p.1) states that: 
In terms of graduates, we want students who are hard-working, disciplined, self-motivated, with a decent knowledge of a broad spectrum of political science, a capacity to research in a variety of ways, and most importantly, to construct a compelling argument.

From these two sets of expectations, one can see that reading critically, analysing texts, and articulating and defending 'compelling arguments' (Department Policy Document, 2014, p.1) are practices connected to the discipline; they mark out Political Science graduates as having particular abilities and dispositions towards thinking and ongoing learning. In order to enable students to master these practices, the department notes that teaching Political Science "concerns [developing students'] capacities for constructing arguments" and creating "the learning culture required to support this essentially the skills and dispositions to support a good argument" (Department Policy Document, 2014, p.1, emphasis added).

An example of a tutorial task students are expected to do, drawn from the course outline/study guide, highlights the creation of the learning culture necessary to develop the skills and dispositions the discipline values, using the knowledge or content that forms part of the first year curriculum:

\section{TUTORIAL THREE: IS POLITICS INEVITABLE? HOW DOES POLITICS AFFECT OUR DAILY LIVES?}

Imagine South Africa in 2030 as you would like it to exist and answer the following questions.

- What will life be like and what would people be doing in an ideal 2030 ?

- $\quad$ Describe the person who could operate successfully in 2030.

- What skills and attributes would they need?

- What needs to be done to achieve the scenario that you've sketched?

- What factors could undermine this scenario?

- Are there trends present now which point to how South African society will actually develop? (POL131 course outline, 2013, p.5, emphasis added) 
This task highlights an approach used in teaching this discipline, to move students deliberately towards developing a more thoughtful and critical disposition, one that enables them to consider issues from more than only one perspective. It highlights the use of the imagination, encouraging students to imagine a particular scenario and apply their present knowledge to that scenario as they consider this set of questions. This kind of task, coming early in their first year, also begins to scaffold them into the process of thinking through argumentation, particularly points four and five in the list, where they would need to justify or reason their answers, rather than just present the answers as fact.

In Political Science, one can argue that the basis for legitimate achievement emanates from the knower structure and therefore that what is valued is the ability for knowers to develop a critical, thoughtful, engaged and curious disposition, and a certain set of aptitudes related to knowledge, such as being able to read analytically, make and defend coherent arguments, and being able to make relevant links between knowledge in the everyday political sphere with theoretical knowledge. The emphasis in this discipline is therefore on social relations to knowledge (SR). Although particular theories or concepts epistemic relations to knowledge (ER) - are often the focus of pedagogy, they are not the basis for claims to legitimacy in Political Science. Political Science thus represents a knower code, with stronger social relations and weaker epistemic relations (ER-, SR+). This is represented heuristically in figure 2 below. 


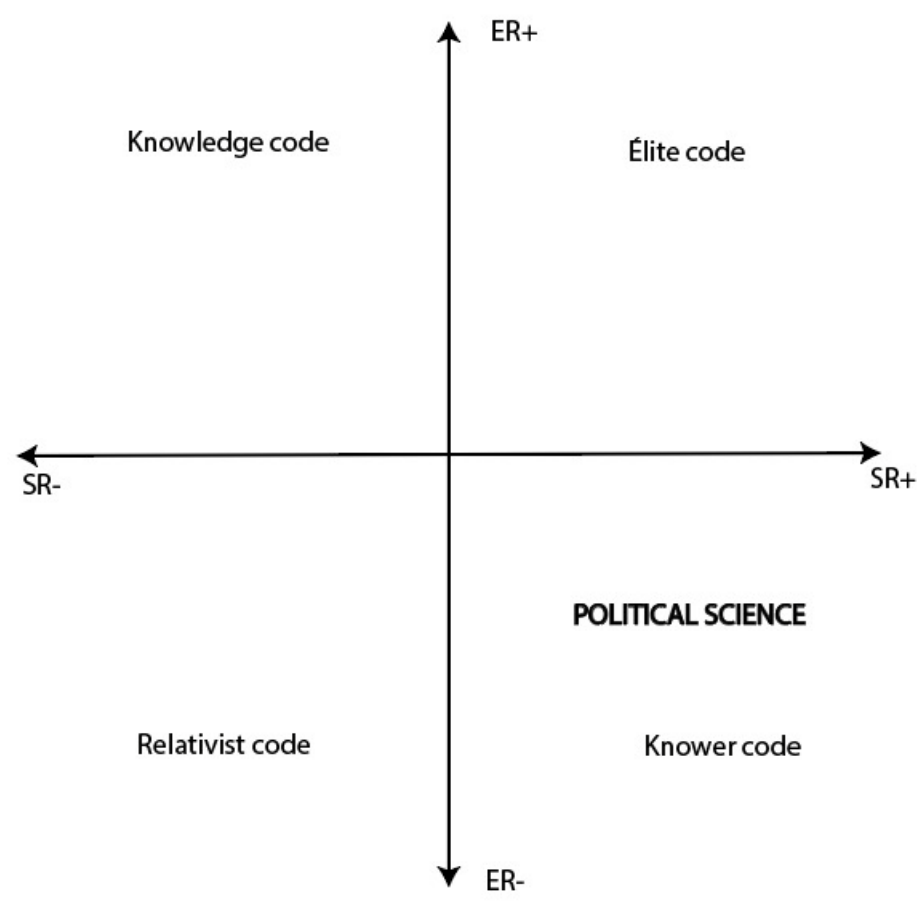

Figure 2: Political Studies as a knower code represented on a Cartesian plane (Clarence, 2014, p.138)

The paper now returns to constructive alignment to consider what the kind of analysis outlined in this section could offer as a way of complementing and enhancing curriculum alignment in disciplines that represent knower codes, like Political Science.

\section{Implications for curriculum: enhancing constructive alignment}

This paper has thus far argued that, while useful in promoting a thoughtful approach to curriculum design and alignment, Bigg' constructive alignment approach has a gap in terms of considering different, non-aggregative forms of knowledge building or learning. This paper has proposed a complementary approach to analysing curricula, particularly those that fall into this gap, with a view to enhancing constructive alignment and its ability to be useful across the disciplinary map. The analysis presented in the previous section, as a small but illustrative example of a curriculum that represents a knower code, 
offers us two key insights and implications for enhancing a constructive alignment approach to curriculum design and enactment.

The first key insight addresses this question: how could Specialisation help us to account for a different kind of knowledge building or learning process, as well as a different way of understanding the knowers we seek to cultivate over time? The question that begins an alignment process should be: what do my learning outcomes need to be to achieve the aims of this course? It is implied that we must consider the bigger picture, but given that knowledge is only tacitly included in Biggs' account of curriculum alignment, and that only certain forms of knowledge-building are included in his analysis, we may well end up using such a tool to focus more narrowly on making sure that just the course we are teaching is aligned within itself, without having the tools to use in considering where and how the course fits into the bigger picture, and even what the bigger picture is. Thus, Specialisation, in helping us to 'code' a discipline and characterise in finer detail what the content or form of that code is within our different contexts, enables us to ask and answer an additional question: Do these outcomes align with the aims of the degree as well as the overall goals of the discipline, in terms of both the knowledge students must learn, and the kinds of knowers we need them to become?

A Specialisation analysis of a discipline could offer lecturers writing curricula in 'siloed' or separately developed and taught courses a less tacit connection to the discipline they are teaching, and to what it is that the discipline itself requires of graduates who will eventually work within the field the discipline references (for example, Law as an academic discipline referencing the wider field of legal practice). I would argue that we need to articulate as clearly as possible exactly what kinds of knowers and knowledge the disciplines aim to nurture and develop over the course of a degree programme in order to select and develop appropriate learning outcomes. For example, Political Science, as a knower code, wants to develop critical, analytical knowers who are able to work with a range of knowledges in different contexts, and are able to make and defend arguments through learning to judge competing knowledge claims and perspectives against their own perspective on a given issue.

We can look again, through a Specialisation lens, at the learning outcomes in the course outline, specifically at what they are asking students to do with the knowledge in this course: 
- Identify, define and describe key concepts in Political Studies, e.g. power, legitimacy and authority.

- Identify, define and describe the key concepts in International Relations, e.g. sovereignty, world order, international anarchy, international political economy, etc.

- Explain Galbraith's theory of power and apply it to South Africa.

- Compare and contrast the key theories of International Relations, e.g. Realism, Liberalism and Marxism.

- Differentiate between and explain selected processes in Political Studies and International Relations, e.g. social activism, development or trade. (Course outline, Introduction to Political Studies, 2013: 1, emphasis added)

If we consider the dominant verbs used here - identify, define, describe, explain - and then consider the most important goal of this discipline - to teach students to construct compelling arguments, we can see these verbs as connected to the knower code, and to the kinds of things students need to do to begin understanding and constructing arguments. Students need to have a knowledge base on which to draw in constructing their own arguments, whether verbally or in writing, so that they do not only have their own prior or everyday knowledge to use. Hence, the course begins with having students describe and show understanding of key concepts, before moving on to comparing and contrasting opposing theoretical perspectives, differentiating between differing political processes.

With a Specialisation analysis, we can go one step further in analysing these outcomes, and wonder whether the lecturers for this course can more explicitly include an initial attempt at getting students to evaluate or analyse a particular issue using the key concepts they have been taught in this course. Perhaps this is beyond the remit of a first semester, first year course, but this analysis offers lecturers teaching in the second semester and in the subsequent years of study a lens on their learning outcomes, to look for ways in which they can build on this foundation and further cultivate within students the desired dispositions, and also teach them the methods required to produce 'compelling arguments' (Departmental Policy Document, 2014, p.1). This 
analysis therefore can connect and align individual courses with the knower code of this discipline, and further align the aims of subsequent or simultaneously offered courses with both this course and with the knower code to enable more overt consideration of how to build or cultivate knowers cumulatively (cf. Maton, 2014).

The second key insights addresses this question: how do lecturers, once they have aligned a curriculum more consciously with their discipline's code, help students to see the code, and achieve the outcomes in ways that begin to cultivate them as knowers? Here I would like to note that seeing the code of a discipline in the terms enabled by a Specialisation analysis can open up different kinds of conversations between lecturers teaching together about how they are designing their curricula, what kinds of outcomes are important, and how they could teach and assess their students. Further, being able to see and characterise a discipline as a knower code of a particular kind (or other specialisation code of a particular kind) can help lecturers to make more overt and visible the tacit expectations they have of their students' classwork, writing and thinking, often communicated through feedback or the kinds of in-class questions and tasks they set (O'Donovan, Price and Rust, 2004). These tacit expectations, if unseen by students, are difficult to meet consistently and successfully, and the result may be a 'hit and miss' effect, with some students getting things right at some points and wrong at others without them (or their lecturers and tutors) necessarily knowing why. A Specialisation analysis, making clear as it can the underlying organising principles of a discipline, or the basis for legitimate achievement, can mitigate against the misses by showing both lecturers and students what is expected in order for students to achieve success, and also how these expectations can be more ably and consistently met over time. If the curriculum, the enactment of it through teaching and tutoring, and the assessments students complete carefully consider and align with the underpinning basis for achievement, it can be argued that success becomes more possible for a greater number of students, as the 'rules' they are being asked to play by become more visible.

\section{Conclusion}

This paper has argued that constructive alignment, as a popular approach to curriculum design, leaves a notable gap in terms of its consideration of different forms of knowledge building, as well as different kinds of people, or 
knowers, that disciplines aim to cultivate. Working from a realist theory of knowledge, that enables an analysis of curriculum focused both on knowledge and knowers without obscuring one or the other, the paper has proposed a complementary tool for curriculum alignment. Drawn from Legitimation Code Theory, the dimension of Specialisation can enable an analysis of the underlying organising principles of disciplines that indicates what the legitimate basis for achievement and success could be. With this analysis in mind, the basis for achievement can be consciously considered by lecturers writing and teaching curricula, such that different forms of knowledge and knower development can be taken into account more critically.

Using specialisation codes as an analytical lens enables lecturers to consider not only the specific course or module they are designing, but also the course or module's place within the degree programme as a whole. Most importantly, this analysis highlights the underpinning organising principles of the discipline and how the stated aims of the courses or modules and the degree programme align with these. In other words, it provides a critical lens that looks beneath the surface of the curriculum to ask whether the learning outcomes, teaching activities, and assessment tasks are appropriate, or adequately expressed to students, given the underlying organising principles of the discipline, conceptualised as a specialisation 'code'. The illustrative case in this paper, Political Science as a knower code, provided a way of showing how such an analysis offers an additional conceptual tool to use with constructive alignment's more practical approach to curriculum design.

Aligning a curriculum, when the underlying code of a discipline has been conceptualised and unpacked, can become less focused on connecting 'content' with 'skills' in teaching and assessment; rather it can shift to aligning teaching and students' learning with the code of the discipline itself. In the case of a knower code, what needs to be aligned across and between years of study is the underlying critical, imaginative and analytical dispositions and aptitudes valued by the discipline, as mastery of these is the basis for achievement. In Political Science, as an example, each course in each year of the undergraduate degree would need to incrementally and cumulatively develop students' ability to read texts with critical and careful comprehension, understand the ways in which the authors are analysing and unpacking political and/or social problems, and further begin to position themselves to make and defend their own arguments. 
Rather than trying to debunk constructive alignment, this paper has taken a cue from Kahn's research (2015), which argues that, given its lack of consideration of horizontal knowledge structures, and the implications for developing students as knowers, this approach to curriculum writing has limited use in higher education as it stands. This paper has picked up that cue and argues that, given that constructive alignment is a popular approach to curriculum writing in higher education in several contexts, what we may benefit from is an additional and complementary conceptual approach to analysing curriculum. Underpinned by a realist theory of knowledge, this complementary approach can offer a wider perspective on the kinds of knowledge and knowers that higher education disciplines, and the intellectual and professional fields they connect to, are trying to nurture and educate over time. Specialisation provides such a lens, and offers us valuable insights into what the organising principles of disciplines could be, how these may shift over time, and how this view can enhance our ability to write, teach and assess aligned and effective curricula.

Acknowledgements

Part of the research this paper is based on was made possible with thanks to an NRF Doctoral Sabbatical Grant in 2013.

\section{References}

Barnett, R. (2000). Supercomplexity and the curriculum. Studies in Higher Education, 25(3): pp.255-265.

Bernstein, B. (1999). Horizontal and vertical discourse: an essay. British Journal of Sociology of Education, 20(2): pp.157-173.

Biggs, J. (1996). Enhancing teaching through constructive alignment. Higher Education, 34: pp.347-364.

Biggs, J. (2012). What the student does: teaching for enhanced learning. Higher Education, Research \& Development, 31(1): pp.39-55. 
Clarence, S. (2014). Enabling cumulative knowledge-building through teaching: A Legitimation Code Theory analysis of pedagogic practice in Law and Political Science. Unpublished PhD diss. Grahamstown: Rhodes University.

Department of Political Studies. (2013). Introduction to Political Studies (POL) 131 Course Outline. Belville, South Africa: University of the Western Cape.

Department of Political Studies. (2014). Departmental Policy Document. Belville, South Africa: University of the Western Cape.

Edström, K. 2008. Doing course evaluation as if learning matters most. Higher Education Research \& Development, 27(2): pp.95-106.

Goodin, R.E. \& Klingemann, H-D. (Eds). (1998). A new handbook of Political Science. Oxford: OUP.

Herrington, J., \& Herrington, T. (2006). Authentic learning environments in higher education. Pennsylvania: Information Science Publishing.

Joseph, S., \& Juwah, C. (2012). Using constructive alignment theory to develop nursing skills curricula. Nurse Education in Practice, 12(1): pp.52-59.

Kahn, P. (2015). Critical perspectives on methodology in pedagogic research. Teaching in Higher Education, 20(4): pp.442-454. DOI: 10.1080/13562517.2015.1023286.

Maton, K. (2000). Recovering pedagogic discourse: A Bernsteinian approach to the sociology of educational knowledge. Linguistics and Education, 11(1): pp.79-98.

Maton, K. (2007). Knowledge-knower structures in intellectual and educational fields. In F. Christie, \& J.R. Martin (Eds), Language, knowledge and pedagogy: Functional linguistic and sociological perspectives. London: Continuum, pp.87-108.

Maton, K. (2014). Knowledge and knowers. Towards a realist sociology of education. London: Routledge. 
Maton, K., \& Moore, R. (2010). Introduction. In K. Maton, \& R. Moore, (Eds), Social realism, knowledge and the sociology of education.

Coalitions of the mind. London and New York: Continuum, pp.1-13.

O’Donovan, B., Price, M., \& Rust, C. (2004). Know what I mean? Enhancing student understanding of assessment standards and criteria. Teaching in Higher Education, 9(3): pp.325-335.

O’Neill, G., \& McMahon, T. (2005). Student centred learning: what does it mean for students and lecturers? In G. O'Neill, S. Moore, \& McMullin, B. (Eds), Emerging issues in the practice of university learning and teaching. Dublin: AISHE, pp.27-36.

Schulman, L.S. (2005). Signature pedagogies in the professions. Daedalus, 134(3): pp.52-59.

Treleaven, L., \& Voola, R. (2008). Integrating the development of graduate attributes through constructive alignment. Journal of Marketing Education, 30(2): pp.160-173.

Wheelahan, L. (2009). Why knowledge matters in curriculum: A social realist argument. London: Routledge.

Sherran Clarence

Centre for Higher Education Research, Teaching and Learning (CHERTL)

Rhodes University

sherranclarence@gmail.com 